\title{
breathless, a Drosophila FGF receptor homolog, is essential for migration of tracheal and specific midline glial cells
}

\author{
Christian Klämbt, ${ }^{1}$ Lillian Glazer, ${ }^{2}$ and Ben-Zion Shilo ${ }^{2,3}$ \\ ${ }^{1}$ Institut für Entwicklungsbiologie, Universität zu Köln, Gyrhofstrasse 17, 5000 Köln 41, Germany; ${ }^{2}$ Department of \\ Molecular Genetics and Virology, Weizmann Institute of Science, Rehovot 76100, Israel
}

\begin{abstract}
A Drosophila homolog of the fibroblast growth factor (FGF) receptor was isolated and structurally characterized. After EMS mutagenesis or imprecise excisions of marked $P$ elements inserted upstream to the gene, a phenotypic series of mutations in the locus was isolated. The mutants exhibit defects in the two embryonic tissues in which the receptor is expressed: the tracheal system and the midline. The tracheal cells fail to migrate in severe mutants and remain within the tracheal pits. Hypomorphic alleles exhibit partial migration of all tracheal branches; thus, the locus was termed breathless (btI). In the midline of the mutant embryos, the posterior pair of midline glial cells begins to migrate anteriorly, but fails to reach the posterior commissure. Abnormalities in cell migration appear to be a common denominator for the btl defects in these two disparate tissues. In hypomorphic mutants the cells exhibit partial migration but follow the normal tracts, suggesting that the presence of this receptor is essential for the ability of the migrating cells to recognize external guiding cues.
\end{abstract}

[Key Words: Receptor tyrosine kinase; FGF; Drosophila embryonic development; cell migration ${ }_{i}$ trachea; midline glia]

Received May 21, 1992; revised version accepted June 29, 1992.

Communication between cells during development is crucial to the determination of cell fate and cell movement. In most cases the cells are multipotent and must probe their environment to receive cues directing the developmental decisions that they have to make. Cellsurface receptors in Drosophila are essential elements in these processes, as they represent the components used by the cell to receive information from its immediate or more distant environment (for review, see St. Johnston and Nüsslein-Volhard 1992). For example, the Toll receptor transmits signals into the ventral part of the syncytial embryo, which set up the polarity of the dorsoventral axis (Hashimoto et al. 1988, 1991). The torso receptor transmits the signals that determine the terminal structures of the embryo (Sprenger et al. 1989). Finally, activation of the sevenless receptor by a ligand on the neighboring R8 cell directs the differentiation of the photoreceptor R7 cell in the eye imaginal disc (Hafen et al. 1987; Krämer et al. 1991; for review, see Rubin 1991).

In addition to the determination of diverse cell fates, developmental processes are comprised of cell migration and extension events. In Drosophila, cell migration is necessary at several stages of development. For example, invagination of the mesoderm and its subsequent dorsal migration requires cell movements (Leptin and

${ }^{3}$ Corresponding author.
Grunewald 1990). Similarly, cell migrations are needed during the formation of the tracheal system. Tracheal cells migrate from the tracheal pits and generate the tracheal tree comprised of branches that reach all tissues of the embryo (Campos-Ortega and Hartenstein 1985; Bier et al. 1989|. For the cell migration events that establish the central nervous system (CNS), the characteristic migration events of the midline cells have been described in great detail (Klämbt et al. 1991). Two of the three pairs of midline glial cells that exist in each segment (the anterior and middle pair| move posteriorly and, thereby, physically separate the anterior and posterior commis sures. The third pair moves anteriorly into the next segment. No specific function has yet been attributed to the latter cells. Mutations that disrupt the normal differentiation or migration of the midline glial cells have been described and include spitz, rhomboid, Star, and faint little ball (flb) (Mayer and Nüsslein-Volhard 1989; Klämbt et al. 1991; Raz and Shilo 1992). Some of these loci encode cell-surface molecules (Schejter et al. 1986; Bier et al. 1990). It is not possible to say, however, whether these cell-surface molecules are specifically involved in the process of cell migration, as the midline glial cells fail to differentiate or die in these mutant backgrounds.

One candidate for a cell-surface receptor that is required for cell migration is a Drosophila fibroblast 
growth factor (FGF) receptor homolog that we have isolated (DFGF-R1). This locus at 70C/D encodes a receptor tyrosine kinase that has all the hallmarks of the FGF receptor subfamily; most notably, it possesses immunoglobulin-like domains at the extracellular region and a split cytoplasmic kinase with a small kinase insert sequence (Glazer and Shilo 1991). A second Drosophila FGF receptor homolog (DFGF-R2) has been isolated recently (M. Beiman, L. Glazer, and B. Shilo, unpubl.). It does not appear, however, to have overlapping functions with the DFGF-R1 protein. The extracellular domains of the two receptors show only $30 \%$ amino acid sequence identity, suggesting that they may recognize a different set of ligands. Furthermore, the two loci do not share common sites of expression during embryogenesis. DFGF-R2 is expressed in the mesoderm, whereas DFGF$\mathrm{R} 1$ was shown to be expressed in the developing tracheal system and the midline cells (Glazer and Shilo 1991).

Chromosomal deficiencies removing the DFGF-R1 locus give rise to mutant embryos in which the tracheal pits form, but the subsequent processes of cell migration and extension do not take place (Glazer and Shilo 1991). Because the chromosomal deficiency that was used removed several loci, it was not possible to conclude unambiguously whether the FGF receptor homolog itself is indeed crucial for tracheal cell migration. Here, we present the isolation of mutations and DNA excisions that specifically affect the DFGF-R1 gene. These mutants represent a phenotypic series of alleles in the locus. The mutants are defective in cell migration in two embryonic tissues in which the receptor is expressed. The tracheal cells display a reduced ability to migrate, and the tracheal tree is not formed. In the midline, the posterior midline glial cells do not complete their anterior migration to reach the posterior commissure. The CNS axon pattern also shows subtle abnormalities. The mutant phenotype demonstrates that the DFGF-R1 receptor is crucial for the migration capacity of different cell types and may even be directly responsible for receiving external cues guiding these intricate cell migration events.

\section{Results}

\section{Structure of DFGF-R1}

The sequence of genomic and cDNA clones of DFGF-R1 has been presented previously (Glazer and Shilo 1991). It showed a cytoplasmic tyrosine kinase domain that is most closely related to the vertebrate FGF receptor subfamily, as well as an extracellular region with three immunoglobulin-like domains. The extracellular sequence was not complete, however, as it did not contain the predicted signal peptide. The sequence was extended by isolation of cDNA clones that encode the amino-terminal domain and by sequencing the parallel genomic region. These sequences showed that the extracellular region of DFGF-R1 contains a hydrophobic signal peptide and two more immunoglobulin-like domains, in addi- tion to the three domains that were identified previously (Fig. 1).

Although the presence of five immunoglobulin-like domains was described for the PDGF receptor subfamily (Yarden and Ullrich 1988), it has not been found previously for members of the FGF receptor subfamily, which typically contain only two or three immunoglobulin-like domains. Nevertheless, DFGF-R1 is clearly a member of the FGF receptor family, as demonstrated by the characteristic size and consensus sequences of the immunoglobulin domains and by the organization of the cytoplasmic kinase domain (Fig. 2).

Alternative splicing processes have been implicated in generating diversity in the number and structure of the immunoglobulin domains of several vertebrate FGF receptors (Reid et al. 1990; Yayon et al. 1992). This region of DFGF-R1, however, does not appear to be modified by alternative splicing, as the cDNA and genomic clones are colinear along the entire extracellular coding sequence. The only intron that was identified in the gene is

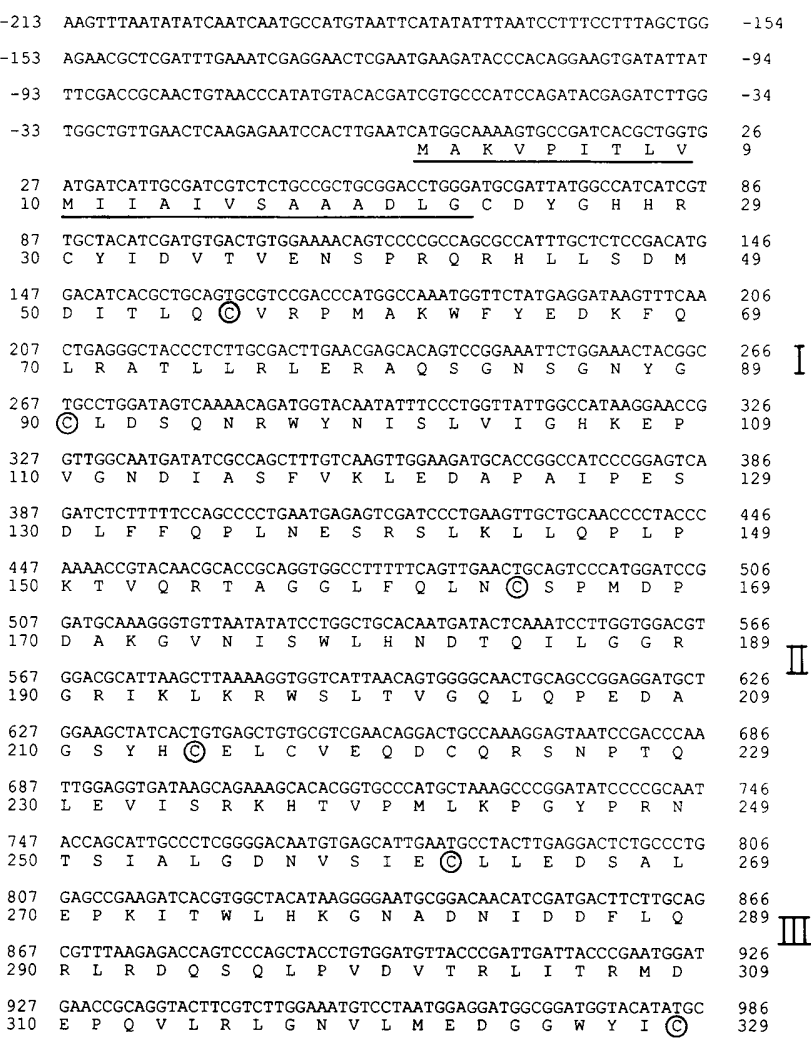

Figure 1. Sequence of DFGF-R1 extracellular domain. The sequence of the amino-terminal three immunoglobulin-like domains at the extracellular region of DFGF-Rl is shown. The hydrophobic signal peptide is underlined. The cysteine residues defining the borders of the immunoglobulin-like domains are circled, and the domain number is shown in Roman numerals. The putative initiator codon was designated as residue 1. Cysteine residue 262 was tentatively marked as 1 in Glazer and Shilo (1991). The putative protein contains 1051 residues, including the signal peptide. 


\section{DFGF-R 1}

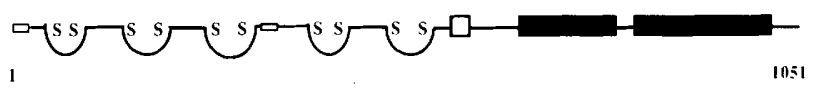

Figure 2. Scheme of the DFGF-R1 protein. ( $\square$ ) The hydrophobic signal peptide and transmembrane domains; $(\boldsymbol{\square})$ the kinase domain. An acidic box typical to FGF receptors is located between the third and fourth immunoglobulin domains, and is stippled.

located within the kinase-coding region (Glazer and Shilo 1991). Primer extensions (not shown) and the 5' sequence of the cDNA clones agree on the localization of the transcriptional start site $\sim 60$ bases upstream to the initiator ATG codon.

\section{Mutations in the DFGF-R1 locus}

Two strategies were used to isolate mutations in the DFGF-R1 locus: imprecise excision of marked P elements and an "F 2 lethal screen" to isolate ethylmethane sulfonate (EMS)-induced mutations. The distinct expression pattern of the gene in the tracheal and midline cells has allowed the identification of two different enhancer trap elements that show a similar pattern of expression and map to the same chromosomal locus (Bier et al. 1989; C. Klämbt and C.S. Goodman, unpubl.). Southern blot analysis was carried out on these two lines to determine their integration sites with respect to the DFGF-R1 locus. The analysis shows that both elements have integrated within several hundred bases of each other fon either side of the genomic $B a m \mathrm{HI}$ site), $2 \mathrm{~kb}$ upstream of the transcriptional start site (Fig. 3). The integration of the elements upstream of the gene agrees with the observation that both 6-81 and $\mathrm{H} 82$ homozygous flies are viable. $\mathrm{H} 82$ homozygotes appear but at a reduced frequency.

Both elements were excised by dysgenic crosses (for details, see Materials and methods), and three excision mutants, which removed DNA sequences in the direction of the DFGF-Rl gene, were further characterized. All retain the genomic sequences $5^{\prime}$ to the integration site, as well as P-element sequences containing the $l a c Z$ gene. This can also be demonstrated by the retention of $\beta$-gal expression in the tracheal pits and midline cells in these embryos. Thus, at least some of the enhancer elements that confer the tissue-specific expression pattern must lie outside the deleted stretches. The three deletions remove different extents of the DFGF-R1 5 ' sequences, but none of them remove the transcription start site. Thus, if residual transcript is being made, it should encode a functional protein.

The transcriptional levels of the locus were examined in embryos homozygous for the 6-81 $\Delta \mathrm{l}$ and $\mathrm{H} 82 \Delta 3$ alleles, by in situ RNA hybridization with a DFGF-R 1

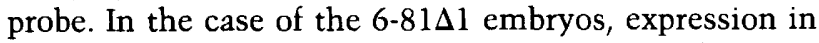
the tracheal pits and midline was observed and is estimated to represent $\sim 10 \%$ of the wild-type levels (Fig.

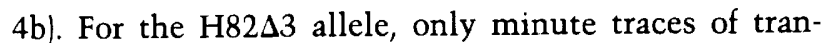
scripts could be detected in the mutant embryos (Fig. 4c).

Another excision termed $\mathrm{H} 82 \Delta 21$ was shown by Southern blot analysis to remove sequences $5^{\prime}$ to the integration site (including some of the DNA encoding the transcript that was identified 5' to DFGF-R1), but to retain the Bluescript sequence of the $P$ element and all genomic sequences located $3^{\prime}$ to it. This excision is homozygous lethal, but was shown to complement to full viability all other excisions that delete sequences $3^{\prime}$ to the integration site. Thus, we can conclude that the phenotypes of the excisions in the direction of the DFGF-R1 gene that lead to a reduction in the level of DFGF-R1 transcripts reflect specifically the consequences of defects in this locus.

In addition, we isolated several EMS-induced mutations in an $\mathrm{F}_{2}$ lethal screen over a small chromosomal deficiency (for details, see Materials and methods). Subsequent genetic analysis revealed one complementation group containing two alleles (LG18 and LG19), which are allelic to the excision mutations of the DFGF-R1 locus.

\section{The tracheal phenotype of DFGF-R1} mutants: breathless

The process of tracheal differentiation and migration can be followed by several markers. Enhancer trap lines allow tracing of the number and position of the tracheal nuclei at all stages of embryogenesis (Bier et al. 1989). Alternatively, antibodies recognizing tracheal membrane antigens [e.g., DFGF-Rl or crumbs (Tepass et al. 1990; Glazer and Shilo 1991)] help to visualize the out-

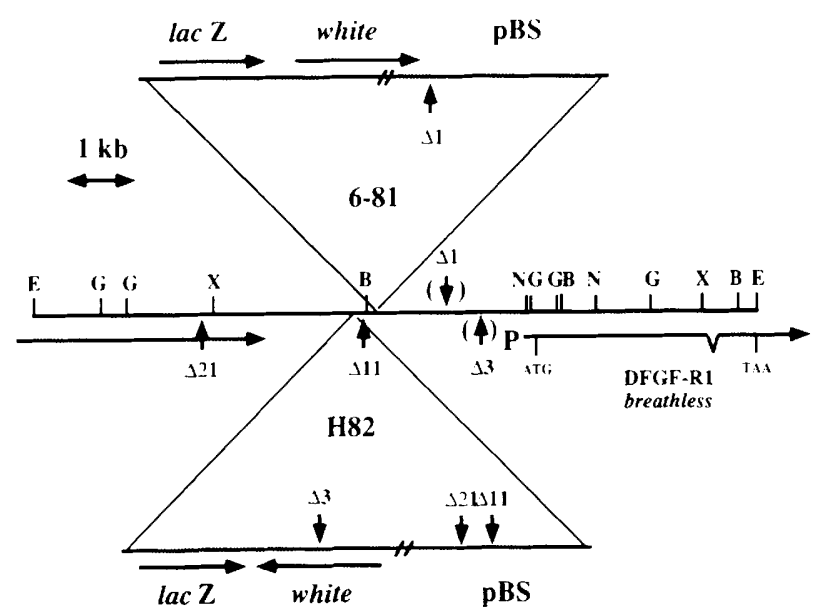

Figure 3. A map of the DFGF-R1 locus and the induced excisions. The breakpoints induced by the imprecise excisions of the enhancer trap elements are shown by arrows. The positions of the deletions in $6-81 \Delta \mathrm{l}$ and $\mathrm{H} 82 \Delta 3$ that map to the $2-\mathrm{kb}$ BamHI-NdeI fragment are shown in parentheses. We could not identify other restriction sites within this fragment that would allow the localization of the positions with greater accuracy. (B) BamHI; (E) EcoRI; (G) BglII; (N) NdeI; (X) XbaI. (P) The site of DFGF-R1 transcription initiation, as mapped by primer extension. 


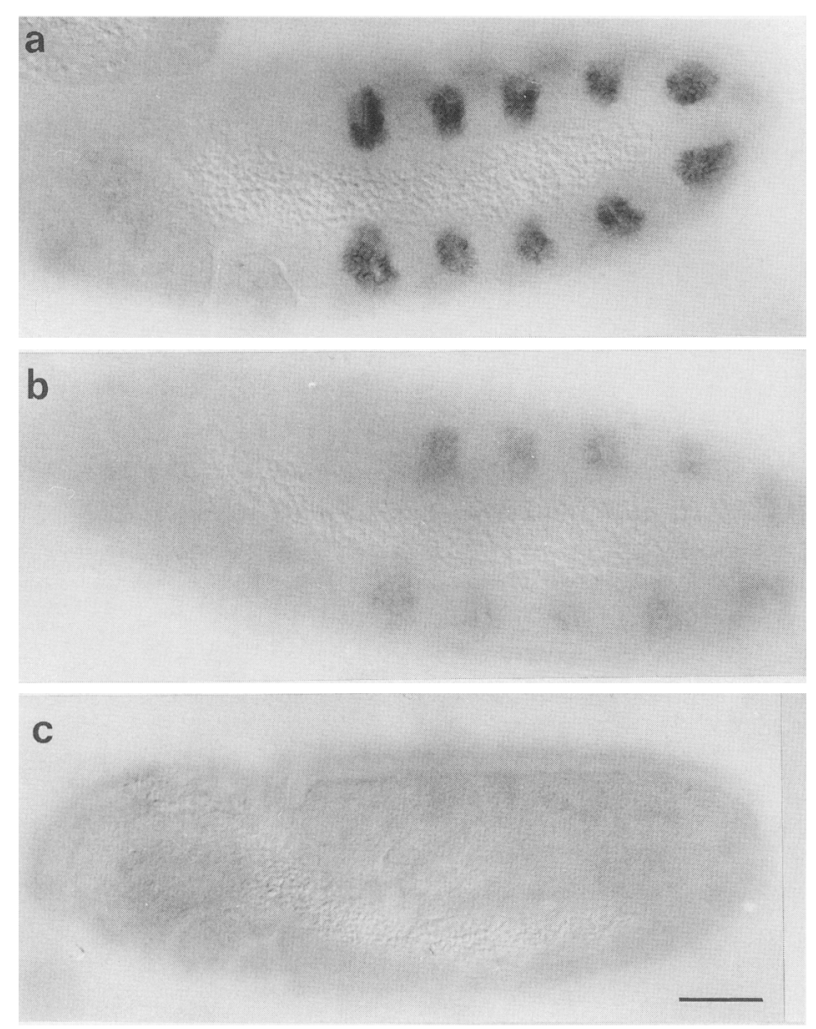

Figure 4. Reduced expression of DFGF-R1 in enhancer excision mutants. Whole-mount in situ hybridization was carried out on wild-type and mutant embryos with the DFGF-R 1 probe. (a) A wild-type stage-12 embryo focused on the tracheal pits. $|b|$ A homozygous 6-81 $\Delta 1$ embryo at the same stage. Residual expression of the gene in the tracheal system and in the midline cells can be detected clearly. From the staining intensity in many mutant embryos that were monitored, we estimate the level of DFGF-R1 transcription to be $10-20 \%$ of the wild-type level. (c) A homozygous H82 33 stage- 12 embryo. In these embryos, only trace amounts of the transcripts can be detected. Bar, $50 \mu \mathrm{m}$.

lines of the cells comprising the tracheal system. Finally, antibodies that recognize components secreted into the lumen of the tracheal tubes were identified in monoclonal antibody screens (N. Patel and C.S. Goodman, pers. comm.) or fortuitously in polyclonal antibody preparations (antiserum 84; N. Walker and B. Shilo, unpubl.). These antibodies are extremely useful in following the normal pattern generated by the tracheal tree and abnormalities that may occur in different mutant backgrounds.

The process of tracheal differentiation during embryogenesis has been divided into two phases /Campos-Ortega and Hartenstein 1985|. First, the cells that will form the tracheal system are generated at stages $10-11$ by cell divisions in the ectoderm, which generate $\leqslant 100$ cells in each of the tracheal pits (G. Manning and M. Krasnow, pers. comm.). In the second phase (encompassing stages 12-17), the entire tracheal system, on each side of the embryo, is generated by the apparent migration and ex- tension of the $\sim 900$ tracheal cells that originated in the 10 tracheal pits.

Our earlier observations have indicated that trachael pits form in embryos homozygous for a chromosomal deficiency of the 70C/D region (Glazer and Shilo 1991). Thus, although DFGF-R1 is expressed from the early stages of tracheal formation, it is not required for the initial invagination of the tracheal precursor cells to form the tracheal pits. These embryos showed, however, that the phase of cell migration is defective. The availability of different alleles specifically affecting the DFGF-R1 locus provides an opportunity to examine directly the role of this locus in tracheal migration. Embryos homozygous for the different alleles were stained with an antibody that marks the lumen of the tracheal tubes (Fig. 5). These alleles define a phenotypic series. The most severe phenotype is observed for the two EMSinduced alleles. Even at late stages of embryogenesis, the tracheal cells do not undergo significant migration; they remain clustered at the site of the tracheal pit. On the basis of this phenotype, we termed the DFGF-Rl locus breathless (btl). Although no migration takes place in the severe alleles (LG18 and LG19), the tracheal lumen antigen that is normally detected by antiserum 84 is secreted into the cavity of the residual tracheal pits. The two EMS-induced alleles appear to represent the complete null phenotype. Embryos homozygous for the LG18 or LG19 alleles display a similar phenotype to embryos in which each of these mutations is carried over a deficiency for the 70C/D chromosomal region (not shown).

The $b t l$ alleles generated by excision of the marked $\mathbf{P}$ elements are hypomorphs. The severity of the phenotypes is in accordance with the residual levels of $b t l$ transcripts that are synthesized by each of the alleles. In $\mathrm{H} 82 \Delta 3$, only very limited migration of the tracheal cells takes place. The cells begin to migrate from the pits and form short stumps of the visceral branches and the dorsal trunk. In $\mathrm{H} 82 \Delta \mathrm{ll}$, the migrations are more pronounced. In several segments, the dorsal trunk is continuous and the branches that normally extend to the gut and CNS are partially formed. Finally, in 6-81 $\Delta 1$ the dorsal trunk is continuous in most segments, and the dorsal, visceral, and head branches are more complete. The hypomorphic nature of these three alleles is also reflected by the fact that their phenotype over a deficiency is more severe than the homozygous phenotype (not shown).

Because expression of $\beta$-gal by the enhancer trap is retained in the hypomorphic $b t$ t alleles, it was possible to follow the fate of the tracheal nuclei in these mutant backgrounds. As judged by fluorescence microscopy, the number of nuclei in the mutants appears similar to wildtype embryos (Fig. 5h). The partial migration that is observed for these hypomorphic alleles is reflected in a limited migration of the nuclei; however, no major loss of cells has occurred. In spite of the failure of these cells to migrate, they express the lumen-specific antigen at the proper time (shown above).

The hypomorphic btl alleles show defects in the formation of all tracheal branches; thus, they appear to be 
Figure 5. The tracheal phenotypes of DFGF-R1 (btI) mutants. Stage-15 embryos were stained with antibody 84 , labeling the lumen of the tracheal tubes. $(a)$ Wild-type embryo; $(b)$ Df. $f z$ GF3b homozygous embryo; $(c)$ LG19 homozygous embyro; (d) $\mathrm{H} 82 \Delta 3$ homozygous embryo; (e) $\mathrm{H} 82 \Delta 11$ homozygous embryo; (f) 6-81 $\Delta 1$ homozygous embryo. The nomenclature of the tracheal branches is according to Rühle (1932). (dt) Dorsal trunk; $(\mathrm{k}$ ) visceral branches. Notes the progressive increase in the formation of the dorsal trunk, and a, d, e, and $\mathrm{k}$ branches, as the severity of the $b t \mathrm{l}$ alleles is reduced. Stage- 15 embryos were also stained with monoclonal anti- $\beta$-gal antibodies to visualize the tracheal nuclei. $\langle g|$ Wild-type 6-81 embyro; $(h)$ H82 $\Delta 3$ homozygous embryo. Bar, $50 \mu \mathrm{m}$.
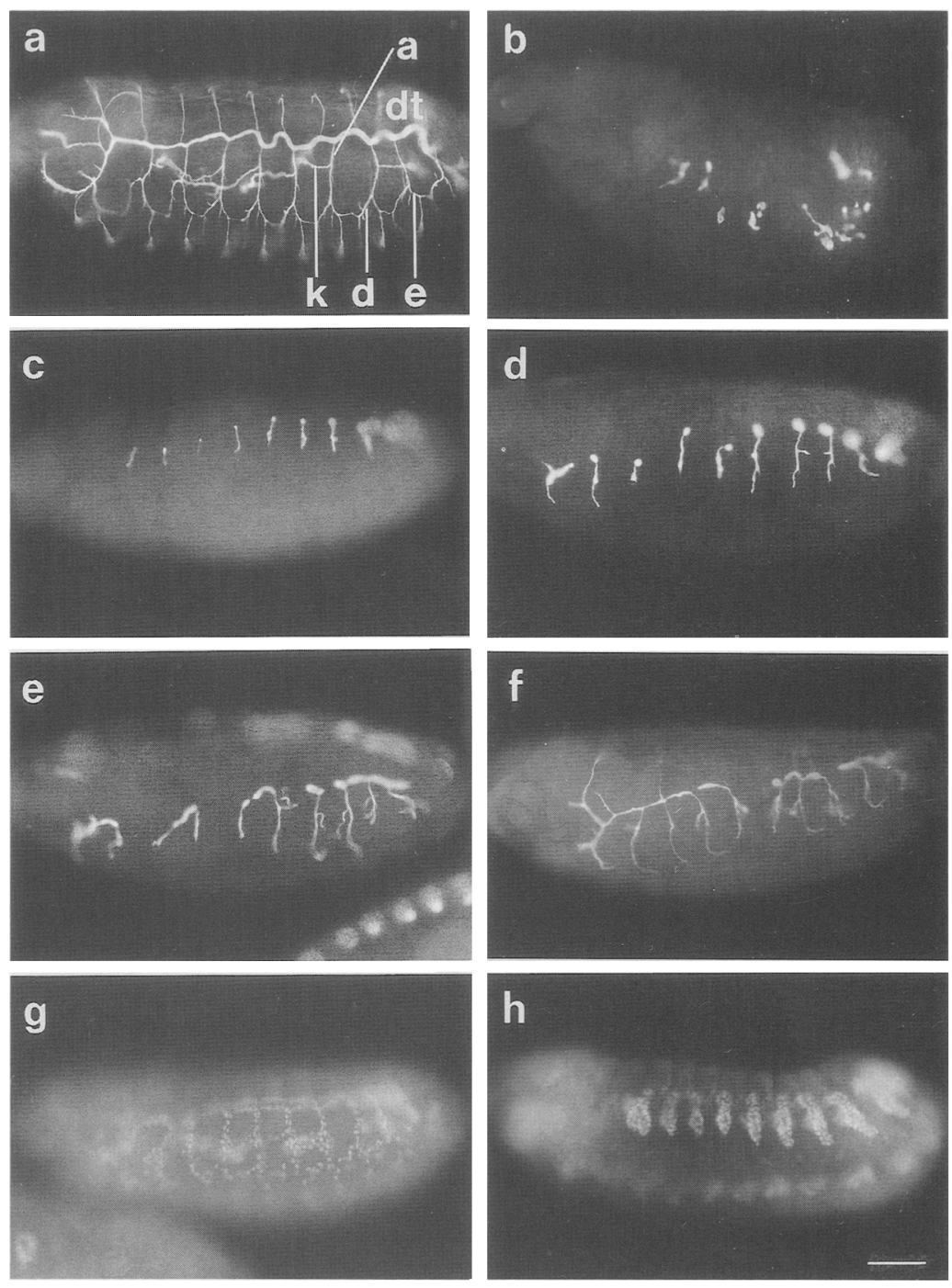

defective in a process common to all migrating tracheal cells. It is important to note that when partial migration of the tracheal cells occurs, the branches appear to form in the normal positions. This would suggest that DFGF$\mathrm{R} 1$ is necessary for the tracheal cells to follow the signals guiding their migration but does not affect the actual migration cues.

\section{Expression of btl in the midline cells}

In addition to btl transcription in the tracheal system, the gene is also expressed in the midline cells of the embryonic CNS (Glazer and Shilo 1991). This expression pattern can be visualized by $\beta$-gal localization in the two enhancer trap lines. Whole-mount in situ hybridization with a $b t l$-specific probe reveals that expression starts just before the onset of gastrulation, as early as stage 5 . Cells at the posterior pole, as well as two groups of ventral cells located at the anterior tip of the embryo, show hybridization signals (Fig. 6a).
During gastrulation, btl expression is detectable in two single-cell-wide stripes flanking the invaginating mesoderm anlage. These cell rows correspond to the mesectodermal precursor cells moving toward the midline, where they meet to form the single row of midline precursor cells (Fig. $6 \mathrm{~b}, \mathrm{c}$ ). It is interesting to note that $b t$ l expression is modulated in a segmental manner from the onset of transcription in the midline. During stage 12, $b t l$ expression is most pronounced in the midline cells of the posterior half of the segment. This includes the ventral unpaired median (VUM) neurons and the posterior pair of midline glial cells. $b t l$ expression in these midline cells continues until the end of stage 12 (not shown).

\section{CNS phenotype of btl}

The formation of segmentally arranged commissures requires a diverse set of cell-cell interactions in the midline of the CNS (Klämbt et al. 1991). Impairment in any of these interactions subsequently leads to defects in the 


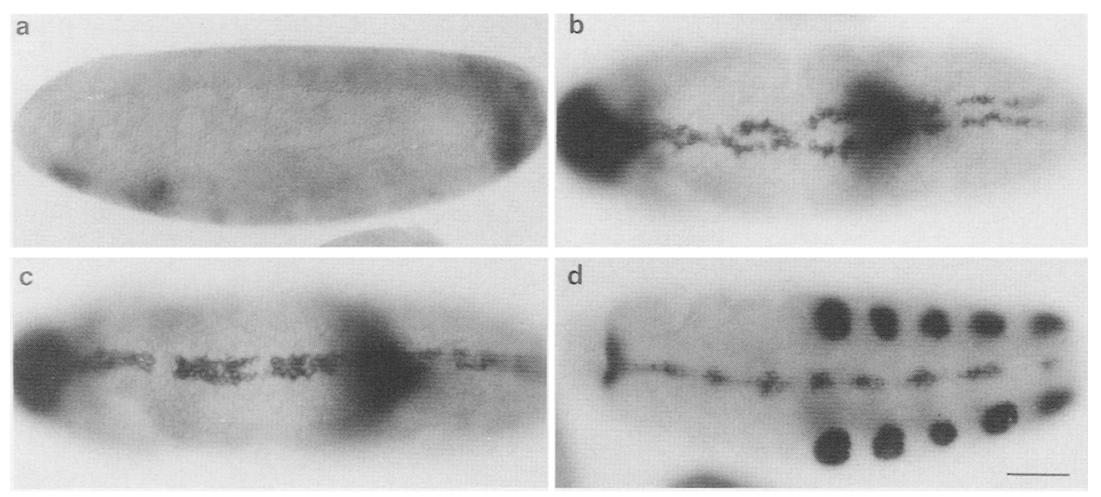

Figure 6. Early transcription of the $b t l$ gene. DFGF-Rl transcripts are first detectable just before the onset of gastrulation. (a) Two groups of cells located ventrally at the anterior tip of the embryo, as well as some cells at the posterior pole, start to express the DFGF-R 1 gene. $(b, c)$ As gastrulation proceeds, two single-cell-wide stripes on each side of the presumptive mesoderm also express the DFGF-R1 gene. Starting from the beginning of transcription to later stages (such as stage 12) in $d$ ), transcription in the midline is modulated in a segmental manner. Bar, $50 \mu \mathrm{m}$.

stereotyped segmental appearance of the commissures. Because DFGF-R1 is a cell-surface receptor that is expressed in the midline cells, we analyzed the CNS axon pattern of different btl mutants (H82 33 and LG19). The homozygous mutant embryos were unambiguously identified on the basis of their tracheal phenotype and by the absence of staining contributed by the "Blue balancer" chromosome. Initially, both commissures are formed normally in btl embryos, and no CNS defects can be seen (not shown). From stage 14 onward, however, irregularities in the arrangement of the commissures are observed (Fig. 7). Instead of the well-defined space between the anterior and posterior commissures in wildtype embryos [where the RP neurons 1,2, and 3 are located (Jacobs and Goodman 1989b)], a smaller irregular and more roundshaped space is seen in homozygous btl embryos \{Fig. 7a,b). This commissural phenotype is slightly more pronounced in LGl9 compared with H82 3 (not shown), in accordance with the more severe tracheal phenotype of LG19. It is important to note that this axon pattern phenotype emerges after the separation of the segmental commissures has taken place.

To address the question of whether any of the midline cells may be responsible for this phenotype, we analyzed the midline cell lineages using antibodies and enhancer trap lines as cell-specific markers (Klämbt et al. 1991). The anterior and middle pair of midline glial cells (MGA and MGM cells, respectively; Jacobs and Goodman 1989a) are present in homozygous btl mutant embryos, but their nuclei sometimes appear slightly displaced. The posterior migration of the MGA and MGM cells, as well as the midline migration of the RP motor neurons, occurs normally in the mutant embryos /data not shown). These glial cells are the midline cells that express the lowest level, if any, of the DFGF-R1 transcript. The VUM neurons form normally and show no defects when stained with the monoclonal antibody $22 \mathrm{ClO}$, which labels their cell surfaces, in addition to other cells. Subtle defects in the position of individual neurons of the VUM cluster or in their final projection pattern, however, may have escaped our attention.

The most striking cellular defect in btl embryos is seen in the posterior pair of midline glial (MGP) cells in each segment. These two glial cells are born just anterior to the MGM cells and then migrate during stage 12 anteriorly into the next segment, where they reach the posterior commissure at the beginning of stage 13 when the segmented commissures have already been separated (Klämbt et al. 1991). In homozygous btl mutant embryos this migration is defective, and the MGP cells remain closer to the anterior commissure of their original segment. As the CNS condenses during later stages of embryonic development, these glial cells are displaced dorsally and the CNS axon pattern phenotype becomes clearly visible (Fig. $7 \mathrm{~d}$ ). The defects in the MGP cells appear to be cell autonomous, as these cells express the $b t l$ gene.

The MGP migration defect and the axon pattern abnormalities are the only CNS phenotypes that we could detect during embryonic development, in spite of the identification of the btl transcript in several midline cell types. Whole-mount in situ hybridization experiments with a rhomboid-specific probe, which labels the mesectodermal precursor cells (Bier et al. 1990), did not reveal any defects in their number or position in btl mutant embryos.

\section{Discussion}

\section{The role of breathless in tracheal migration}

The process of tracheal formation represents an amenable biological system in which the intricate regulation of cell migration can be dissected experimentally. The tracheal tree is formed by cell migration and extension in a period of only several hours (stages 12-17, 8-16 hr after egg lay). Finally, the structures are generated from a finite number of cells $\mid \sim 900$ cells for each side of the embryol.

Several key issues remain unanswered. It is not known whether cell lineage plays a role in tracheal morphogenesis or whether all tracheal cells are equivalent and choose their migration path stochastically. Although it appears that the cues for migration must be provided by the microenvironment, it is not known whether these signals are diffusible or anchored to cell membranes or to the extracellular matrix. Finally, the cues for the formation of the different tracheal branches may be identical. 

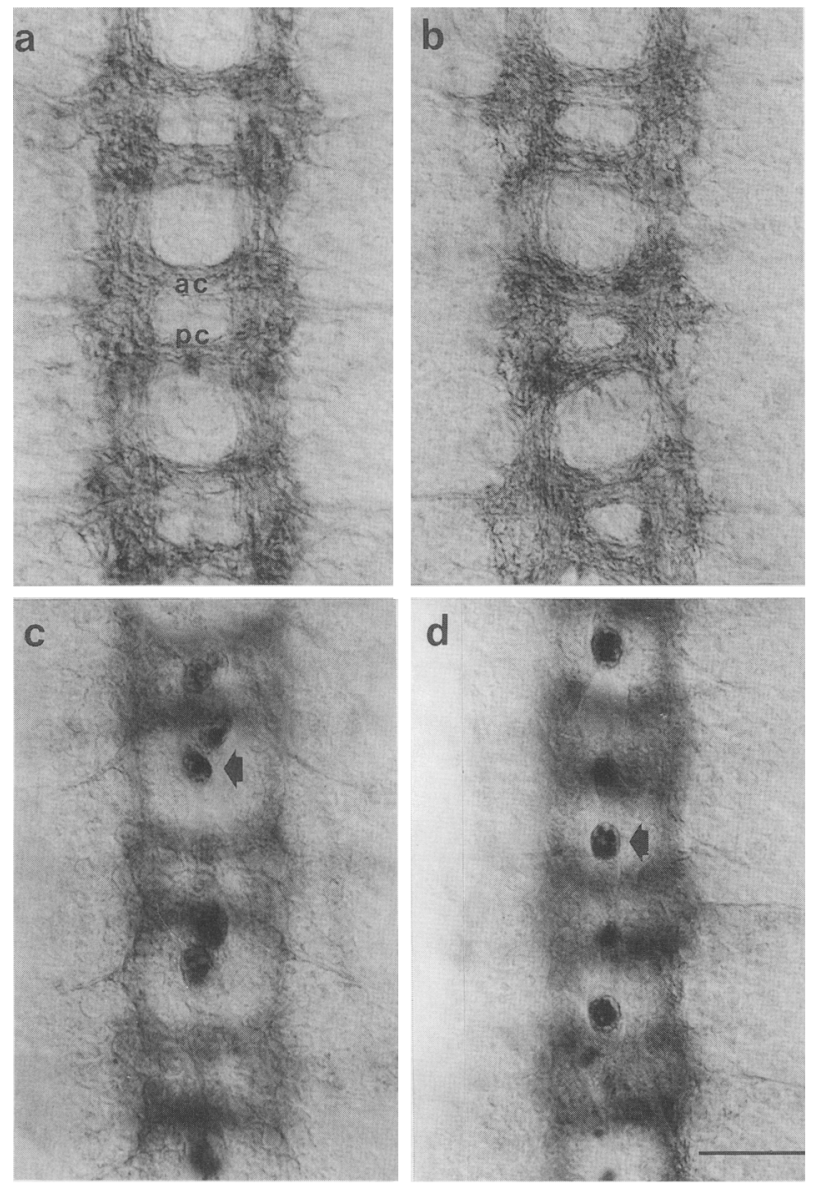

Figure 7. The glial cell and CNS axon pattern phenotype of $b t]$ embryos. The CNS axons are labeled with mAb BP102 and horseradish peroxidase (HRP) immunohistochemistry. The MGP cells are labeled by anti- $\beta$-gal polyclonal antibodies, followed by phosphatase detection of the $\mathrm{H} 82$ enhancer. All photographs are frontal views of dissected embryonic CNS. (a) The wild-type axon pattern of a dissected stage-16 CNS. Note the regular appearance of the anterior commissure (ac) and the posterior commissure $(\mathrm{pc})$, which define a square-like space between them. $(b)$ The CNS axon pattern of a homozygous LG19 btl embryo shows irregularities in the arrangement of the commissures; most notably the commissures are separated, but the anterior and posterior commissures now define an irregular, more rounded space between them. (c) Wild-type stage-16 CNS (in the genotype H82 $33 / T M 3$ ). Double staining of the CNS axons and the H82 enhancer element. (d) In a homozygous H82 33 mutant embryo, the MGP cells (arrow) are defective in their anterior migration toward the posterior commissure of the next segment and are displaced to the dorsal surface of the CNS. The final position of the MGP cells is usually anterior to the commissure where these cells have been born. They are never found to be associated with the posterior commissure (in contrast with the wild-type embryo in $c$ ), but occasionally (as in the top segment of $d$ ), they may be found close to the posterior commisure. Bar, $20 \mu \mathrm{m}$.

Alternatively, each branch may be guided by different signals that could be recognized by a diverse set of cellsurface receptors.
The $b t l$ alleles described in this work represent a phenotypic series in which tracheal cell migration is defective. No migration takes place in the severe alleles, whereas partial migration of all branches is observed in the weaker alleles. In situations of partial migration, the tracts that do form appear normal. This observation suggests that DFGF-Rl activity is crucial for the tracheal cells to recognize the cues for migration, rather than generation of these migration signals. It is plausible to envisage the cues for tracheal migration as external signals that are presented by the tissues that are in contact with the migrating tracheal cells, such as the ectoderm or mesoderm.

The ability of mutations in a single locus to alter the migration of all tracheal branches is dramatic and suggests two possible models for the role of $b t l$ in tracheal migration. One option is that btl is required by all tracheal cells to respond to the external cues for migration. According to this model, the receptor is not directly responsible for detecting these cues, which may differ for each subset of branches. For example, activation of the DFGF-Rl protein may be necessary to trigger a set of transcription factors that would allow the expression of receptors that will detect the external cues for migration. According to this possibility, the potential ligand of DFGF-R I need not be localized, as it is only necessary for priming the tracheal system to respond to the external cues.

An alternative option is that DFGF-R1 itself is the receptor through which the external cues guiding migration are transmitted. This notion is supported by the observation that in the $b t l$ alleles generated by imprecise excision of marked P elements there is a strict correlation between the level of DFGF-R1 expression and the extent of migration of the tracheal cells. The ligand triggering DFGF-R1 may be soluble or it could be anchored to the cell membrane, the extracellular matrix, or to heparin-sulfate proteoglycans. FGF-like molecules in vertebrates were shown to be anchored in a nonsoluble form (for review, see Ruoslahti and Yamaguchi 1991). Furthermore, in several cases, FGF can be displayed in a biologically active form only when it is associated with heparin-sulfate proteoglycans (Yayon et al. 1991). The implication of this model is that the ligand of DFGF-R1 would be made (in a diffusible or insoluble form) by neighboring cells in a prepattern that precedes the migration of the tracheal cells. Although the identities of the cells marking each of the migration tracts at different positions need not be identical, they may be producing the same signaling molecule (i.e., the putative ligand of DFGF-R1).

FGF has been implicated in the regulation of cell migration in vertebrate systems. It was shown to be a potent angiogenic factor, capable of stimulating division and migration of endothelial cells toward high local concentrations of FGF (Folkman and Klagsbrun 1987). Because FGF is released as a soluble factor, the growing blood vessels that are attracted to the region develop in a random fashion, rather than in a highly organized and stereotypic structure. In this respect, the formation of the tracheal tubes in the embryo may be more similar to 
the construction of blood vessels during embryogenesis or organogenesis in vertebrate organisms, where the vessel pattern is very similar in all individuals.

\section{The role of btl in glial migration}

Although the $b t l$ gene is expressed from the early stages of mesectoderm differentiation, no phenotype is seen in these cells during gastrulation of mutant embryos. The absence of any phenotypes at this stage may be accounted for by postulating that the function of DFGF-R 1 at this stage is redundant or nonessential. Alternatively, although the gene may be transcribed in the mesectoderm precursor cells during gastrulation, some time may elapse until the processing of the protein and its translocation to the plasma membrane is completed. The DFGF-R1 protein could be detected by immunohistochemistry only after the mesectodermal cells meet at the midline, after the completion of gastrulation (Glazer and Shilo 1991).

A characteristic defect was detected, however, in the MGP cells of $b t l$ embryos. These cells do not complete their migration toward the posterior commissure of the next segment, and stay closer to the anterior commissure, where they were originally born and eventually become displaced dorsally. It is not clear how defects in the migration of MGP cells may lead to the commissure phenotype. During the initial formation of the commissures, the MGP cells are not thought to play an instructive role, as they are located at a distance from the commissures (Klämbt et al. 1991). The defects that are observed in btl embryos suggest that the MGP cells may be needed for the stabilization of the final commissure pattern during later stages. For example, these cells may normally stop the posterior migration of the MGM cells preventing them from growing around the posterior commissure. Therefore, when the MGP cells do not reach their final destination in the mutant embryos, development of the commissures is initially normal. As the nerve cord condenses, however, the MGM cells may overgrow the posterior commissure. Instead of separating the two commissures, they now "pull" them together, thus generating an irregular spacing between them. Alternatively, the axon pattern defects could be the result of a change in the VUM cluster of midline neurons or in the MGA and MGM cells. No major positional changes were detected in the VUM neurons, which express the btl gene. Similarly, no alteration in the positions of the MGA and MGM cells, which do not express detectable levels of $b t 1$ RNA, was observed. It is possible, however, that subtle changes in the interaction between these cells, which may be crucial for late commissural morphogenesis, could also contribute to the commissural defects of $b t l$ embryos. Therefore, the precise causal relationship between the altered MGP cell migration and the commissural phenotype remains to be demonstrated.

\section{Possible common themes}

Although the embryonic tracheal and midline cells rep- resent completely different lineages, it is striking that btl appears to play a similar role in both cases. The migration of the tracheal cells, as well as that of the MGP cells is not completed in $b t l$ mutant backgrounds. Thus, DFGF-R 1 emerges as a central player in processes of cell migration for both tissues.

There is one additional tissue expressing the gene. During stages 11-13, a small group of ectodermal cells that will eventually form the duct of the salivary gland show btl expression (not shown). In forming the duct, these cells normally migrate a short distance to connect the salivary gland with the pharynx (Campos-Ortega and Hartenstein 1985). No apparent defects in the formation of salivary duct have been observed, however, when the development of the duct cells was followed in $\mathrm{H} 82 \Delta 3$ mutant embryos stained with anti- $\beta$-gal antibodies.

Several receptor tyrosine kinases in Drosophila have been shown to play a pivotal role in different contexts of cell determination (for review, see Shilo 1992). The torso protein transmits into the syncytial embryo the signals that define the position of the terminal structures (Sprenger et al. 1989). Drosophila epidermal growth factor receptor (DER)/flb has a diverse set of roles during embryogenesis, which include the determination of the identity of the ventral ectoderm (Schejter and Shilo 1989; Raz and Shilo 1992). In the egg chamber, alleles of the DER locus (torpedo) have demonstrated that the receptor is also required to transmit signals that determine the fate of the dorsal follicle cells (Schüpbach 1987; Price et al. 1989). Finally, the sevenless receptor is required in the eye imaginal disc for the future R7 photoreceptor cell to initiate neuronal differentiation, after triggering by the environment (Hafen et al. 1987; Krämer et al. 1991; Rubin 19911.

The functions of $b t l$ described in this discussion appear different from the functions of the previously characterized Drosophila receptor tyrosine kinases. In btl mutants, the identity of the cells that normally express the receptor does not appear to be altered. The tracheal cells continue to display tracheal markers, such as an antigen that is secreted into the tracheal lumen or the specific $\beta$-gal expression from the enhancer trap inserted upstream to the $b t l$ gene, which marks the tracheal cells throughout their development. Likewise, all midline cells express normally the diverse differentiation markers that were tested. Although the identity of the tracheal and midline cells is normal, these cells fail to follow their typical migration routes. Thus, DFGF-R1 appears to represent a crucial element in the migration processes of these cells.

In mice, the involvement of a receptor tyrosine kinase in processes of embryonic cell migration has been suggested on the basis of the phenotype of the White spotting mutations in the c-kit locus. The phenotype of these mutations affects three populations of cells: neural crestderived melanocytes; primordial germ cells; and hematopoietic stem cells. The same tissues are similarly altered by mutations in the Steel locus, which encodes the ligand of the kit receptor (for review, see Silvers 1979|. Steel was shown to be expressed during embryo- 
genesis in cells associated with migratory pathways and homing sites of melanoblasts, germ cells, and hematopoietic stem cells (Matsui et al. 1990). The Steel protein exists in a soluble as well as a cell-surface form. A mutation encoding a Steel protein in which the transmembrane and cytoplasmic domains are deleted, but the soluble form of the protein is intact $\left\langle S I^{d}\right)$, results in developmental defects in the same three lineages typically affected by Steel and White mutations (Brannan et al. 1991; Flanagan et al. 1991). Thus, the membrane-associated form of Steel may be crucial for guiding the migration and homing of embryonic cells, by triggering the kit receptor at very restricted sites.

In conclusion, this work has demonstrated the central role of DFGF-R1 in diverse processes of embryonic cell migration. Many questions concerning the precise function of the receptor in regulating these processes remain open. The key to understanding some of these issues may be the ligand. Future studies, including the identification and characterization of the ligands triggering DFGF-Rl, should tell whether activation of the receptor is a prerequisite for tracheal cells to follow different migration tracts. Alternatively, the signal provided by the ligand may mark different paths of cell migration, which could be recognized directly by activation of the receptor encoded by $b t l$.

\section{Materials and methods}

\section{Fly strains}

Two chromosomal deficiencies uncovering the $70 \mathrm{C} / \mathrm{D}$ region, kindly provided by the Bloomington stock center, were used. if $z$ GF3b (70B-70D6) and $f z$ GSla (70C6-15-70E4-6)). The 6-81 enhancer trap line (Bier et al. 1989) was kindly provided by L. Jan and Y.N. Jan (University of California, San Francisco). The H82 line containing the P-lwB element was generated by the enhancer trap screen carried out in C.S. Goodman's laboratory (C. Klämbt and C.S. Goodman, unpubl.). The following enhancer trap lines were used in this study to follow the differentiation of the midline cells: AuI, which labels the MGP cells; AA142, which labels all midline glial cells; and AE60, which labels the VUM neurons (Klämbt et al. 1991).

\section{Genetic manipulations}

To generate mutations in the DFGF-RI locus, excisions of two enhancer trap elements inserted upstream of the gene were induced, and the events of imprecise excision were scored. Males homozygous or heterozygous for the $6-81$ or $\mathrm{H} 82$ insertions were crossed to females carrying the $S b \mathrm{P}[\Delta 2-3]$ chromosome. Progeny males containing the $w$ first chromosome and the enhancer trap third chromosome over $S b \mathrm{P}[\Delta 2-3]$, were mated to $\mathrm{W} /+; \mathrm{Xa} /+$ females. White-eyed $X a$ males /representing excisions of the enhancer trap) were pair-mated to $f z \mathrm{GF} 3 \mathrm{~b} / T M 3 \mathrm{Sb}$ females. Lines in which no progeny of the genotype enhancer chromosome/Df. $f z G F 3 b$ were scored as imprecise excision events leading to lethality. These lines were characterized further for allelic complementation.

An $F_{2}$ lethal screen was carried out to isolate EMS-induced mutations in the DFGF-R1 locus. Three- to five-day-old males homozygous for the rucuca chromosome were exposed to 25 mM EMS in 1\% sucrose solution for $16-20 \mathrm{hr}$ as described in
Grigliatti (1986). They were subsequently crossed to $\mathrm{ru} \mathrm{cu}$ Pr ca/TM6B females. $F_{1}$ rucuca/ru cu $P_{I}$ ca progeny males were pair-mated to Df. $f z \mathrm{GF} 3 \mathrm{~b} / \mathrm{TM} 3 \mathrm{Sb}$ females. One thousand six hundred pair matings were followed, and lines without rucuca/ $f z G F 3 b$ progeny were characterized further. They were mated to $f z G S 1 a / T M 3 S b$ females to identify lethal mutations on the rucuca chromosome, which map to the chromosomal region defined by the overlap between the two deficiencies. Four such lines were identified and shown to define three complementation groups (LG18 and LG19; LG12 and LG9). The complementation group defined by the LG18 and LG19 mutations was shown to be allelic to the excision mutations in the DFGF-R1 locus.

\section{Molecular biology}

To isolate cDNA clones containing the $5^{\prime}$ region of the DFGF$\mathrm{Rl}$ transcript, an embryonic 3- to 12 -hr cDNA library (Poole et al. 1985) was screened with a 7-kb XbaI genomic fragment of DFGF-R 1 , labeled by random priming. One clone, with an overlap to the previously isolated cDNA clones, was identified. This clone was shown to include the entire 5 '-coding sequence and a stretch of 5 '-noncoding sequence. Using this probe we have also identified a clone containing the $3^{\prime}$ region of a transcript en coded by a gene located upstream to the DFGF-R1 locus.

cDNA and genomic clones of DFGF-RI were sequenced according to the Sanger protocol by use of the Promega or Sequenase (U.S. Biochemical) kits, and synthetic primers. Primer extension was performed according to Sambrook et al. (1989) using as a template $10 \mathrm{mg}$ of total embryonic RNA and a synthetic primer located $60 \mathrm{bp}$ downstream to the DFGF-R1 initiator codon.

To determine the sites of insertion of the enhancer trap elements, as well as the size and location of the excisions, Southern blot analysis was carried out. Total genomic DNA $(1-2 \mu \mathrm{g})$ was digested with restriction erzymes and analyzed by probes prepared from different genomic or cDNA fragments of the DFGF-R1 gene. The position of each breakpoint within a restriction fragment on the DFGF-R1 map could therefore be determined.

\section{RNA in situ hybridization and immunostaining}

To determine the residual level of DFGF-R1 transcripts in embryos homozygous for various excisions, the excision chromosome was maintained over a TM3 balancer chromosome containing a lacZ gene driven by the hunchback promoter (kindly provided by W. Driever). Embryo collections were stained for 10 min with X-gal. This short staining was sufficient to allow the detection of $l a c Z$ expression contributed by the Blue balancer, but did not stain the sites of DFGF-R1 expression by the intact $l a c Z$ gene within the residual enhancer element. After the short exposure to X-gal, embryos were washed in PBS and $0.1 \%$ Triton X-100, and processed further for RNA in situ hybridization according to standard protocols (Tautz and Pfeifle 1989). Embryos were probed with a digoxigenin-labeled 2.2-kb DFGF-R 1 cDNA fragment. During the staining of alkaline phosphatase, the reaction was carried out for a limited time, in an attempt to retain a linear relationship of color intensity.

Embryos were immunostained according to standard procedures (Ashburner 1989), followed by a secondary antibody conjugated to either horseradish peroxidase or rhodamine (Jackson Laboratories). The tracheal-specific antibody (84) was generated fortuitously by injection of acrylamide into guinea pigs. To visualize $\beta$-gal expression, a monoclonal antibody (Promega) or a rabbit polyclonal antibody (Cappel, USA) was used. The CNS 
was visualized by mAb BP102 kindly provided by N. Patel and C.S. Goodman.

\section{Acknowledgments}

We are grateful to C.S. Goodman, in whose laboratory the enhancer trap line $\mathrm{H} 82$ was isolated by one of us (C.K.), for his generous support. We also thank the following people for providing us with valuable reagents. L. Jan and Y.N. Jan for the 6-81 enhancer line, N. Walker for the 84 antibody, J. Campos-Ortega for providing laboratory space for one of us (C.K.) and stimulating discussions, and A. Klaes for help with in situ hybridization experiments. We also thank $M$. Krasnow and $E$. Raz for critical reading of the manuscript. This work was supported by grants from the Bundes Ministerium für Forschung und Technologie and Deutsche Forschungsgemeinschaft to C.K., and by grants from the National Institutes of Health (GM35998) and Israel Academy of Sciences to B.S.

The publication costs of this article were defrayed in part by payment of page charges. This article must therefore be hereby marked "advertisement" in accordance with 18 USC section 1734 solely to indicate this fact.

\section{References}

Ashburner, M. 1989. Drosophila: A laboratory manual. Cold Spring Harbor Laboratory Press, Cold Spring Harbor, New York.

Bier, E., H. Vaessin, S. Shepard, K. Lee, K. McCall, S. Barbel, L. Ackerman, R. Carretto, T. Uemura, E. Grell, L.Y. Jan, and Y.N. Jan. 1989. Searching for pattern and mutations in the Drosophila genome using P-lacZ vector. Genes \& Dev. 3: 1273-1287.

Bier, E., L.Y. Jan, and Y.N. Jan. 1990. rhomboid, a gene required for dorsoventral axis establishment and peripheral nervous system development in Drosophila melanogaster. Genes \& Dev. 4: 190-203.

Brannan, C.I., S.D. Lyman, D.E. Williams, J. Eisenman, D.M. Anderson, D. Cosman, M.A. Bedell, N.A. Jenkins, and N.G. Copeland. 1991. Steel-Dickie mutation encodes a c-Kit ligand lacking transmembrane and cytoplasmic domains. Proc. Natl. Acad. Sci. 88: 4671-4674.

Campos-Ortega, J.A. and V. Hartenstein. 1985. The embryonic development of Drosophila melanogaster. Springer-Verlag, Berlin, Germany.

Flanagan, J.G., D.C. Chan, and P. Leder. 1991. Transmembrane form of the kit ligand growth factor is determined by alternative splicing and is missing in the $S I^{d}$ mutant. Cell 64: 1025-1035.

Folkman, J. and M. Klagsbrun. 1987. Angiogenic factors. Science 235: 442-447.

Glazer, L. and B.-Z. Shilo. 1991. The Drosophila FGF receptor homolog is expressed in the embryonic tracheal system and appears to be required for directed tracheal cell extension. Genes \& Dev. 5: 697-705.

Grigliatti, T. 1986. Mutagenesis. In Drosophila: A practical approach (ed. D.B. Roberts), pp. 39-58. IRL Press, Oxford, England.

Hafen, E., K. Basler, J.E. Edstrom, and G.M. Rubin. 1987. sevenless, a cell-specific homeotic gene of Drosophila, encodes a putative transmembrane receptor with a tyrosine kinase domain. Science 236: 55-63.

Hashimoto, C., K.L. Hudson, and K.V. Anderson. 1988. The Toll gene of Drosophila, required for dorsal-ventral embryonic polarity, appears to encode a transmembrane protein. Cell
52: 269-279.

Hashimoto, C., S. Gerttula, and K.V. Anderson. 1991. Plasma membrane localization of the Toll protein in the syncytial Drosophila embryo: Importance of transmembrane signalling for dorsal-ventral pattern formation. Development 111: 102 l-1028.

Jacobs, J.R. and C.S. Goodman. 1989a. Embryonic development of axon pathways in the Drosophila CNS. I. A glial scaffold appears before the first growth cones. /. Neurosci. 9: 24022411.

- 1989b. Embryonic development of axon pathways in Drosophila CNS. II. Behavior of pioneer growth cones. $I$. Neurosci. 9: 2402-2411.

Klämbt, C., R. Jacobs, and C.S. Goodman. 1991. The midline of the Drosophila central nervous system: A model for the genetic analysis of cell fate, cell migration, and growth cone guidance. Cell 64: 801-815.

Krämer, H., R.L. Cagan, and S.L. Zipursky. 1991. Interaction of bride of sevenless membrane-bound ligand and the sevenless tyrosine-kinase receptor. Nature 352: 207-212.

Leptin, M. and B. Grunewald. 1990. Cell shape changes during gastrulation in Drosophila. Development 110: 73-84.

Matsui, Y., M. Zsebo, and B.L.M. Hogan. 1990. Embryonic expression of a haematopoietic growth factor encoded by the $S I$ locus and the ligand for c-kit. nature 347: 667-669.

Mayer, U. and C. Nüsslein-Volhard. 1988. A group of genes required for pattern formation in the ventral ectoderm of the Drosophila embryo. Genes \& Dev. 2: 1496-1511.

Poole, S.J., L.M. Kauvar, B. Drees, and T. Kornberg. 1985. The engrailed locus of Drosophila: Structural analysis of an embryonic transcript. Cell 40: 37-43.

Price, J.V., R.J. Clifford, and T. Schüpbach. 1989. The maternal ventralizing locus torpedo is allelic to faint little ball, an embryonic lethal, and encodes the Drosophila EGF receptor homolog. Cell 56: 1085-1092.

Raz, E. and B.-Z. Shilo. 1992. Dissection of the faint little ball $(f l b)$ phenotype: Determination of the development of the Drosophila central nervous system by early interactions in the ectoderm. Development 114: 113-123.

Reid, H.H., A.F. Wilks, and O. Bernard. 1990. Two forms of basic fibroblast growth factor receptor-like mRNA are expressed in the developing mouse brain. Proc. Natl. Acad. Sci. 87: 1596-1600.

Rubin, G.M. 1991. Signal transduction and the fate of R7 photoreceptor in Drosophila. Trends Genet. 7: 372-377.

Rühle, H. 1932. Das larvale tracheensystem von Drosophila melanogaster meigen und seine variabilität. $Z$. Wiss. Zool. 141: 159-245.

Ruoslahti, E. and Y. Yamaguchi. 1991. Proteoglycans as modulators of growth factor activity. Cell 64: 867-869.

St. Johnston, D. and C. Nüsslein-Volhard. 1992. The origin of pattern and polarity in the Drosophila embryo. Cell 68: 201219.

Sambrook, I., E.F. Fritsch, and T. Maniatis. 1989. Molecular cloning: A laboratory manual. Cold Spring Harbor Laboratory Press, Cold Spring Harbor, New York.

Schejter, E.D. and B.-Z. Shilo. 1989. The Drosophila EGF receptor homolog (DER) gene is allelic to faint little ball, a locus essential for embryonic development. Cell 56: 1093-1104.

Schejter, E.D., D. Segal, L. Glazer, and B.-Z. Shilo. 1986. Alternative $5^{\prime}$ exons and tissue-specific expression of Drosophila EGF receptor homolog transcripts. Cell 46: 1091-1101.

Schüpbach, T. 1987. Germ line and soma cooperate during oogenesis to establish the dorsoventral pattern of egg shell and embryo in Drosophila melanogaster. Cell 49: 699-707.

Shilo, B.-Z. 1992. The role of receptor tyrosine kinases in Droso- 


\section{Klämbt et al.}

phila development. FASEB I. (in press).

Silvers, W.K. 1979. White spotting, patch and rump white. In The coat colors of mice: A model for gene action and interaction. pp. 206-241. Springer-Verlag, New York.

Sprenger, F., L.M. Stevens, and C. Nüsslein-Volhard. 1989. The Drosophila gene torso encodes a putative tyrosine kinase. Nature 338: 478-483.

Tautz, D. and C. Pfeifle. 1989. A non-radioactive in situ hybridization method for the localization of specific RNAs in Drosophila embryos reveals translational control of the segmentation gene hunchback. Chromosoma 98: 81-85.

Tepass, U., C. Theres, and E. Knust. 1990. crumbs encodes an EGF-like protein expressed on apical membranes of Drosophila epithelial cells and required for organization of epithelia. Cell 61: 787-799.

Yarden, Y. and A. Ullrich. 1988. Growth factor receptor tyrosine kinases. Annu. Rev. Biochem. 57: 443-478.

Yayon, A., M. Klagsbrun, J.D. Esko, P. Leder, and D.M. Ornitz. 1991. Cell surface, heparin-like molecules are required for binding of basic fibroblast growth factor to its high affinity receptor. Cell 64: 841-848.

Yayon, A., Y. Zimmer, S. Guo-Hong, Y. Yarden, A. Avivi, and D. Givol. 1992. A confined variable region confers ligand specificity on fibroblast growth factor receptors: Implications for the origin of the immunoglobulin fold. EMBO /. 11: 18851890 . 


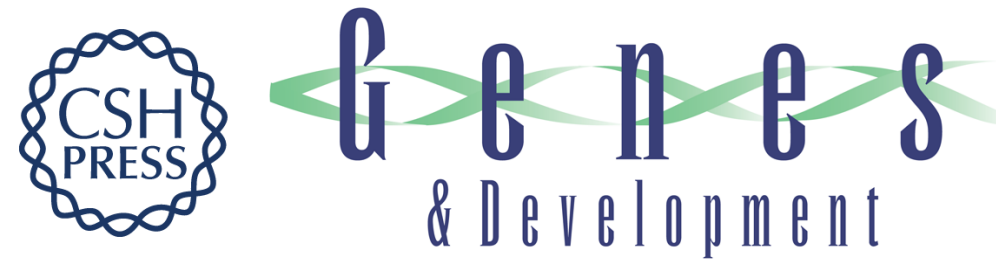

\section{breathless, a Drosophila FGF receptor homolog, is essential for migration of tracheal and specific midline glial cells.}

C Klämbt, L Glazer and B Z Shilo

Genes Dev. 1992, 6:

Access the most recent version at doi:10.1101/gad.6.9.1668

References This article cites 33 articles, 13 of which can be accessed free at: http://genesdev.cshlp.org/content/6/9/1668.full.html\#ref-list-1

License

Email Alerting

Service

Receive free email alerts when new articles cite this article - sign up in the box at the top right corner of the article or click here.

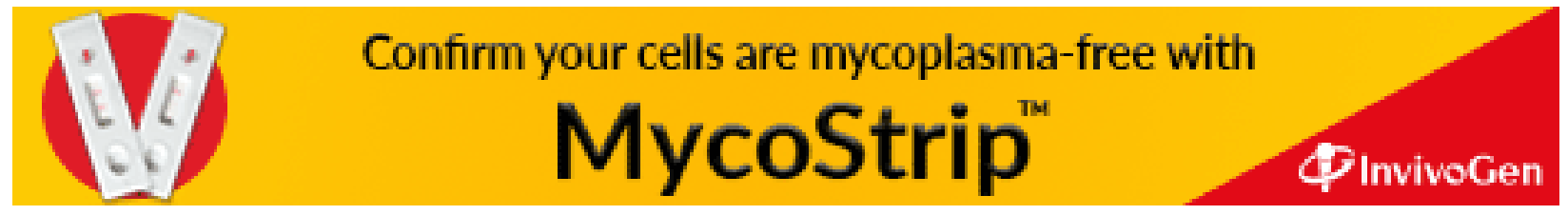

